\title{
Trueba Atienza, Carmen y Sergio Pérez Cortés, eds. Dignidad: perspectivas y aportaciones de la filosofía moral y la filosofía política. México: Universidad Autónoma Metropolitana-Anthropos, 2018.379 pp.
}

\author{
Francisco Miguel Ortiz Delgado ${ }^{1}$
}

$\mathrm{E}$ 1 libro que nos ocupa es un texto compuesto por doce capítulos, cada uno escrito por un investigador distinto; todos los capítulos consisten en análisis filosóficos en torno a un tema eje indicado por el título: la dignidad. En esta reseña, realizaré una revisión cronológico-diacrónica del tratamiento de la dignidad por los doce investigadores, para otorgar una idea clara a los posibles lectores de en qué épocas se concentró cada una de las reflexiones.

Dignidad: perspectivas y aportaciones de la filosofía moral y la filosofía política es un texto coordinado y editado por los investigadores Carmen Trueba Atienza y Sergio Pérez Cortés, profesores de la Universidad Autónoma Metropolitana Iztapalapa (México), poseedores de una amplia trayectoria en la investigación filosófica, en especial en el área de la filosofía griega antigua y en el área de la filosofía política y moral en general. Tal trayectoria les permitió reunir y escoger con esmero y pertinencia a escritos de especialistas provenientes de diversos países de América Latina: Argentina, Chile, Colombia, México y Perú.

En el capítulo uno, tenemos que María Isabel Santa Cruz realiza un estudio de la dignidad en tres diálogos de Platón, donde el personaje de Alcibíades, un griego con "gran dignidad", le sirve a la autora como otro eje "real" para el tratamiento del tema. El capítulo dos, escrito por Raúl Gutiérrez Bustos, también revisa la "dignidad" en Platón, pero en este caso en el diálogo la República (no considerado en el capítulo de Santa Cruz); los otros dos temas que sirven para la reflexión sobre la dignidad son el mito de Er, un

1 Doctorado en Humanidades (División Ciencias Sociales y Humanidades) por la Universidad Autónoma Metropolitana, Iztapalapa, México. Profesor en la Universidad Autónoma Metropolitana-Cuajimalpa, México. Correo electrónico: fmiguelod@gmail.com 
personaje originario de la "histórica" Panfilia (región situada entre las antiguas Licia y Cilicia, en la provincia de Antalya de la actual Turquía) y que le serviría a Platón para ilustrar sus ideas en torno a la moral y a la "vida" después de la muerte; y el comportamiento de Sócrates.

Así como los dos primeros capítulos tienen en común el tratamiento de una misma temporalidad: la Antigüedad clásica griega, los dos siguientes tratan un mismo periodo: la Edad Media occidental. El capítulo tres, de la autoría de Francisco Piñón Gaytán, realiza una reflexión general sobre la "dignidad" en la Edad Media y en él se tratan a filósofos que van desde Tertuliano hasta Tomás de Aquino; incluso, la cronológicamente amplísima cavilación de Piñón no se concreta a la Edad Media, sino que nos lleva hasta la Edad Moderna al hablar de autores como Francisco Suárez, Nicolás Maquiavelo, Immanuel Kant o hasta Friedrich Nietzsche y Heidegger. El capítulo cuarto, escrito por Teresa Santiago Oropeza, tiene objetivos más concretos: aborda la dignidad en la Edad Media, pero se especializa en dilucidar su papel en la guerra; su reflexión hace bien en centrarse en interesantes aspectos de la dignidad en la obra de Agustín de Hipona o de Hugo Grocio, así como en los “códigos de caballería” medievales (desarrollados en los siglos XII a XIV).

Los capítulos cinco y seis están dedicados al más conspicuo filósofo del siglo XVIII, a saber: Kant. En el capítulo cinco, Dulce María Granja Castro entrega una reflexión que, en un primer momento, consiste en un recuento de las influencias históricas y filosóficas de las que Kant disfrutó para el desarrollo de su concepto de dignidad; en un segundo momento, la autora se centra propiamente en el pensamiento del filósofo alemán y nos provee de subcapítulos con títulos como "El principio supremo de la moral" o "Racionalidad y dignidad"; en un tercer momento, se expone el pensamiento de Kant a la luz de algunos de sus intérpretes más actuales. El capítulo seis, escrito por Vicente Durán Casas, radica en una inmersión y disección de la ética kantiana.

Los capítulos siete y ocho nos llevan a la filosofía europea más sobresaliente del siglo XIX. En el capítulo siete, Sergio Pérez Cortés aborda la dignidad en la Filosofía del derecho, de Hegel; Pérez explica las interrelaciones entre la dignidad y las cuestiones como el trabajo, la propiedad privada, el autorrespeto, el capitalismo o los sindicatos, interrelaciones que plantea el pensamiento hegeliano. El capítulo ocho está dedicado a Hegel, así como a Karl Marx y a Kant; Gustavo Leyva Martínez nos provee en este capítulo de una somera visión en conjunto de la dignidad en los tres filósofos mencionados.

Los últimos cuatro capítulos se centran en el "largo siglo XX", como diría Eric Hobsbawm, así como en lo que va del siglo XXI. En los últimos ciento veinte años, la noción de dignidad se ha visto sacudida y cuestionada como nunca, en especial tras el Holocausto, y estos capítulos lo hacen notar. El capítulo nueve aborda al pensamiento de Robert Nozick y las consecuencias que tuvo el Holocausto para el concepto de dignidad; se trata este capítulo de un sugerente análisis realizado por Felipe Schwember Augier, quien, entre otras cosas, explica que Nozick concluyó que él mismo ya no podría hacer una "filosofía optimista, edificante, constructiva", "como si el Holocausto y los demás sucesos del siglo XX no hubieran tenido lugar", siendo la dignidad un concepto impertinente en la actualidad. El capítulo diez, proveído por Dora Elvira García, habla de la relación que posee la dignidad con la paz, la violencia, así como con el concepto griego de phronesis.

El penúltimo capítulo, escrito por Carmen Trueba Atienza, se concentra en "el enfoque de las capacidades" de los pensadores Martha Nussbaum y Amartya Sen, revisando no solo el concepto de dignidad, sino también problemas contemporáneos muy acuciantes como la discriminación, la exclusión, la adicción 
a los estupefacientes, la prostitución, el sexismo, el aborto, la depresión, la clonación o la injusticia en general. El libro cierra con un capítulo dedicado a la reflexión de las interrelaciones entre la dignidad y las migraciones, este último un tema que ha atraído la mayor atención de los medios de comunicación y, por ello, de toda la población mundial de hoy día; su autor, Daniel Loewe, provee al lector de una serie de "datos duros" sobre las migraciones en el mundo durante los últimos setenta años, datos que permiten estudiar y deliberar con mayor precisión sobre estos temas.

Sin duda, el libro Dignidad pone de nuevo sobre la mesa de la discusión filosófica latinoamericana a la "idea" (o ideal) de dignidad. Cada capítulo nos insta (de forma intencional o no) a profundizar más, en especial si se pone atención y se toma nota de la bibliografía que emplea cada uno de los doce autores. El texto entra en el conjunto de estudios monográficos que reúne deliberaciones de diversos investigadores en torno a una misma "idea" o "concepto", formato ya clásico en el campo académico; por ejemplo, es similar en tema (y en ser un esfuerzo colectivo) a Dignity: A History (2017) o a The Cambridge Companion to Human Dignity (2014).

Pero la compilación de Trueba y de Pérez se distingue del primero de los dos libros mencionados, y de muchos otros, en que no consiste (según se barrunta de lo que he expuesto en los párrafos anteriores) en un análisis de la "dignidad" a través de cada una de las épocas de la historia occidental, sino más bien primordialmente en reflexiones sobre la dignidad en el pensamiento de autores de diversas épocas (el hecho de que los capítulos estén ordenados de forma cronológica no significa que el libro es una "historia de las ideas" o una "historia conceptual"). Dignidad se distingue de The Cambridge Companion, y de muchos otros libros, en que no posee un abordaje interdisciplinario sobre la dignidad, sino uno eminentemente filosófico. Se trata, pues, de un libro diferente de muchos otros que se pueden encontrar en la bibliografía reciente, en tanto desde América Latina nos muestra los debates en torno al concepto de dignidad a través de filósofos que van desde un Platón hasta una Nussbaum, así como se distingue porque el 41,66 \% de los capítulos están escritos por mujeres, en tanto cinco de los doce capítulos son de autoría femenina, algo que no se puede decir de los otros dos libros editados por prestigiosas universidades que he mencionado, ${ }^{2}$ ni lamentablemente se puede decir de muchos otros libros colectivos académicos.

\section{Bibliografía}

Debes, Remy, ed. Dignity: A History. Nueva York: Oxford University Press, 2017. https://doi.org/10.1093/acprof:o so/9780199385997.001.0001

Düwell, Marcus, Jens Braarvig, Roger Brownsword y Dietmar Mieth, ed. The Cambridge Companion to Human Dignity: Interdisciplinary Perspectives. Cambridge: Cambridge University Press, 2014. https:// doi.org/10.1017/CBO9780511979033

2 De los diecisiete "apartados" de los que consta Dignity: A History, solo cuatro están escritos por mujeres (23,52 \%). De los 62 capítulos del The Cambridge Companion, solo aproximadamente un 14,51 \% fue escrito por mujeres. 